\title{
The Effect of Using Balance ball on the Functional Level of People with Crohn's Cut
}

Dr/ Walid Hussein Hassan

Introduction and research problem

The exercise of sports activities is a knowledge of its origins, objectives, rules and philosophy. As a human being, it is necessary to understand the nature of evolution and maintain its integrity.

The advantages of the locomotor therapy are its use for all ages, different types of injuries, diseases, deformities, all types of physical tissues, in various stages, maintaining the health and fitness of the patient, restoring flexibility of the joints and muscle fibers, developing the abilities and functional skills, strengthening the working muscles, and achieving the educational and psychological goals of effective participation of the injured in treatment. For his positive psychological effect. (69:21) (32:23)

Therapeutic Exercise is a type of exercise that is given to improve the general muscular performance of the body and strengthen the muscles, bones, joints and ligaments.
These movements are based on a scientific and planned basis according to the condition of the patient in order to stimulate or restore the normal functions of the injured part or maintain its current state or increase its efficiency,

The body reacts with it to rehabilitate the injured part, often choosing the type of exercise and its performance according to the goal of the treatment, as well as diagnosing the condition and the treatment requirements (7: 4) (51:6)

Anterior

cruciate ligament injury is one of the most serious injuries to the athlete's future, due to the importance of cruciate ligament in maintaining the frontal stability of the joint, in the sense that it prevents the slide of the trachea bone on the thigh bone and prevents the extension of the knee joint. (57: 8)

There are some factors that lead to or help in the injury of the cruciate ligament and all knee injuries such as weakness of the surrounding muscles 
affecting the movement of the knee and the inconsistent movements may be the result of poor rehabilitation after long injuries and constant stress and this leads to the knee joint or the muscles working involuntary movements In different directions, resulting in occasional injuries to the knee (41: 9) (16:19)

The athlete has been severely injured or not proficient in performing the basic skills of the activity correctly, in addition to the injuries of the goalkeeper's performance. The skill of the goalkeeper is different, and therefore his number of programs is different from the rest of the members. The team. (79:16)

There are many tools and aids that have been deployed recently can be used to help develop the fitness elements of the skills and each of these tools character and their special impact and that the tools and assistive devices are important and effective in the positive impact on the training and good extraction it raises the activity and enthusiasm of practitioners as well as a means
In this sense, the researcher used one of the modern aids that she believes is expected to raise the level of fitness, namely Balance ball (24).

It is a training device invented by David Wick in 1999 and called Bose is a shortened word for Bose Sides Utilized and meant to be used on both sides, and the brand name Dynamo and its number Aslo45 Art .No

The Balance ballis a training device for balance, strength, ability and cardiovascular improvement. It is a Balance ballon a flat base of $55 \mathrm{~cm}$. It is used on both sides, whether the ball is half circular or flat. It is equipped with two resistance ropes (Ropes) on both sides of the base. Its maximum length becomes $120 \mathrm{~cm}$ with a weight equivalent of $7 \mathrm{~kg}$ (25)

Through the study of the researcher from the previous studies (2), (7), (13), (14) and the work of the researcher in the field of exercise and rehabilitation of sports injuries, they found that the use of the Balance ballof the devices that help to achieve balance of the body 
It is important to find the best methods to develop the balance of motor and stability of the injured and you because the balance is the first engine that is built on the process of rehabilitation of the sports injured, so the idea of this research came to the program by using Aerial Balance ball Training and Profiling In the functional level of patients with cruciate ligament injury.

\section{Research goal}

The aim of this study is to identify the effect of the use of aerodynamic training on the functional level of patients with cruciate ligament injury

\section{Research hypotheses}

There were statistically significant differences between the averages of the tribal and remote measurements in the level of functional efficiency in patients with the cruciate ligament cut.

-There were statistically significant differences between the averages of the pre and post measurements in the level of functional efficiency in patients with cruciate ligament injury control group.

-There were statistically significant differences between the mean of the two dimensional measurements in the experimental and control groups in the level of functional efficiency in patients with cruciate ligament injury and in favor of the experimental research group.

\section{Research plan and procedures \\ Research Methodology}

The researcher used the experimental method of the two groups, one experimental and the other the control and remote, in order to suit the nature of the research and to achieve its objectives and mandates.

\section{Community and Sample Search:}

The study sample was chosen in the intentional manner. The researcher was chosen with the total cut of the front cruciate ligament, which led to knee surgery. Endoscopic surgery was performed. The participants were in the various sports of the municipality of Mahalla and Ghazal Mahalla. determined as experimental group, (8) determined as a control group, the data were determined to moderate the data in age, height, weight،

\section{Conditions for sample selection \\ -Have surgery for 4 weeks.}


-The patient has been subjected to a rehabilitation program to develop the level of motor mobility of the knee a step prior to the proposed program using the Balance ball to develop the balance stage.

-Be in the first stage of physical therapy (installation and configuration)

-The wound has healing.

-Ensure that the health status is correct to start the proposed rehabilitation exercises.

- The consent of the injured to participate and attend regularly to conduct the program

\section{Data collection tools}

The researcher used the following tools and devices to make measurements for the study:

\section{Data collection tools}

A: Physical measurements

1) length to the nearest centimeter.

2) Weight in kilograms.

3) The upper and lower muscles of the knee are affected by the centimeter.

\section{B: Physical measurements:}

1) The fixed muscle strength of the muscles of the front and back thigh.

2) Strength of the muscles of the back leg in terms of muscle circumference. r) The motor range of the knee joint.

4) Fixed balance of the knee.

Devices and tools used in the search:

\section{A: Devices used:}

1- A standardized medical balance to measure the weight to the nearest $\mathrm{kg}$.

$r$ - Resistameter to measure the length of the nearest centimeter.

3- Genometr to measure the motor range of the knee joint.

s-fixed balance measuring device.

- Argometer.

6-Two pneumatic ball valves.

7- Balance measurement: using

a special device to measure (lateral balance left and right, back and front)

\section{B: Tools used:}

- $\quad$ Stopwatch to measure time and record tests.

- measuring tape to measure the muscle circumference.

- Multi-weight weights.

- $\quad$ crushed ice bags.

- $\quad$ Expert feedback form.

- $\quad$ The proposed rehabilitation program.

General conditions to consider when implementing the program

- Warm up for the purpose of activating the circulatory 
system through general exercises and take into account the calm and gradual rhythm.

- Give some exercises for the joints near the place of injury and heat the muscles that work on them.

- Do some exercises to develop and regulate breathing (breathing and exhalation) and improve pulmonary ventilation.

- $\quad$ Taking into account the psychological state of the injured and the importance of dialogue with them.

- Give appropriate exercise in the case of other organic diseases (taking into consideration the health situation in the case of other diseases such as heart and pressure.

- Graduation in the implementation of exercises is easy to hard and simple to composite.

- $\quad$ Avoid fatigue, stress and stop immediately after fatigue

- Balance work throughout the body and not focus on the affected knee

- View and discuss the results

- $\quad$ First: Display the results

Table (1)

The significance of the differences between pre - and post measurement in the level of some functional variables in the experimental group $\mathrm{N}=8$

\begin{tabular}{l|c|c|c|c|c|c|c|c|c}
\hline \hline \multicolumn{1}{c|}{ Tests } & \multirow{2}{*}{$\begin{array}{c}\text { measuring } \\
\text { unit }\end{array}$} & \multicolumn{2}{c|}{$\begin{array}{c}\text { Pre } \\
\text { measurement }\end{array}$} & \multicolumn{2}{c|}{$\begin{array}{c}\text { Post } \\
\text { measurement }\end{array}$} & $\begin{array}{c}\text { Difference } \\
\text { between } \\
\text { the two } \\
\text { averages }\end{array}$ & $\begin{array}{c}\text { Improvement } \\
\text { rate }\end{array}$ & $\begin{array}{c}\text { Value (T) } \\
\text { Calculated }\end{array}$ & $\begin{array}{c}\text { Level of } \\
\text { significance }\end{array}$ \\
\hline $\begin{array}{l}\text { The motor } \\
\text { range of the } \\
\text { knee joint }\end{array}$ & $\mathrm{Cm}$ & 70.66 & 0.21 & 161.25 & 0.62 & 90.59 & $128.20 \%$ & 4.98 & Significance \\
\hline $\begin{array}{l}\text { Frontal } \\
\text { balance }\end{array}$ & Degree & 7.61 & 0.21 & 9.98 & 0.25 & 2.37 & $31.14 \%$ & 4.17 & Significance \\
\hline Rear balance & Degree & 7.33 & 0.36 & 10.9 & 0.41 & 3.57 & $48.70 \%$ & 4.21 & \\
\hline Balance left & Degree & 6.14 & 0.24 & 9.78 & 0.27 & 3.64 & $59.28 \%$ & 3.91 & Significance \\
\hline Balance right & Degree & 6.51 & 0.11 & 9.60 & 0.41 & 3.09 & $47.46 \%$ & 3.71 & Significance \\
\hline $\begin{array}{l}\text { Circumference } \\
\text { of muscles to } \\
\text { leg muscles }\end{array}$ & Cm & 31.52 & 0.87 & 38.21 & 0.98 & 6.69 & $21.22 \%$ & 4.17 & Significance \\
\hline $\begin{array}{l}\text { Peripheral } \\
\text { muscles of the } \\
\text { thigh muscles }\end{array}$ & $\mathrm{Cm}$ & 36.52 & 0.62 & 45.98 & 0.14 & 9.46 & $25.90 \%$ & 4.22 & Significance \\
\hline \hline
\end{tabular}

Tabular value at the significance level $(0.05)=1.895$

Table (1) shows differences between the statistically significant averages of pre and post 
measurements in the level of experimental sample functional efficiency of the

\section{Table (2)}

The significance of the differences between the pre - and post measurement in the level of some functional variables in the affected control group $N=8$

\begin{tabular}{l|c|c|c|c|c|c|c|c|c}
\hline \multirow{2}{*}{ Tests } & \multirow{2}{*}{$\begin{array}{c}\text { Unit } \\
\text { measurement }\end{array}$} & \multicolumn{2}{c|}{$\begin{array}{c}\text { Pre } \\
\text { measurement }\end{array}$} & \multicolumn{2}{c|}{$\begin{array}{c}\text { Post } \\
\text { measurement }\end{array}$} & $\begin{array}{c}\text { Difference } \\
\text { between } \\
\text { the two } \\
\text { averages }\end{array}$ & $\begin{array}{c}\text { Improvement } \\
\text { rate }\end{array}$ & $\begin{array}{c}\text { Value (T) } \\
\text { Calculated }\end{array}$ & $\begin{array}{c}\text { Level of } \\
\text { significance }\end{array}$ \\
\hline \hline $\begin{array}{l}\text { The motor } \\
\text { range of the } \\
\text { knee joint }\end{array}$ & $\mathrm{Cm}$ & 70.44 & 0.17 & 101.32 & 0.52 & 30.88 & $43.83 \%$ & 3.21 & Significance \\
\hline $\begin{array}{l}\text { Frontal } \\
\text { balance }\end{array}$ & Degree & 7.55 & 0.18 & 8.20 & 0.24 & 0.65 & $8.60 \%$ & 2.61 & Significance \\
\hline Rear balance & Degree & 7.30 & 0.16 & 8.44 & 0.36 & 1.14 & $15.61 \%$ & 2.14 & Significance \\
\hline Balance left & Degree & 6.10 & 0.02 & 7.15 & 0.51 & 1.05 & $17.21 \%$ & 2.62 & Significance \\
\hline Balance right & Degree & 6.45 & 0.05 & 7.24 & 0.34 & 0.79 & $12.24 \%$ & 2.74 & Significance \\
\hline $\begin{array}{l}\text { Circumference } \\
\text { of muscles to } \\
\text { leg muscles }\end{array}$ & Cm & 31.98 & 0.77 & 33.98 & 0.31 & 2.00 & $6.253 \%$ & 3.28 & Significance \\
\hline $\begin{array}{l}\text { Peripheral } \\
\text { muscles of the } \\
\text { thigh muscles }\end{array}$ & $\mathrm{Cm}$ & 36.68 & 0.64 & 39.52 & 0.18 & 2.84 & $7.740 \%$ & 3.11 & Significance \\
\hline \hline
\end{tabular}

Tabular value at the significance level $(0.05)=1.895$

Table (2) shows measurements in the level of statistically significant differences between the averages of pre and post

Table (3)

The significance of the differences between the two dimensional measurements in the level of some functional variables among the patients in the experimental and control groups $N=16$

\begin{tabular}{l|c|c|c|c|c|c|c}
\hline \hline \multirow{2}{*}{ Tests } & $\begin{array}{c}\text { Unit } \\
\text { measurement }\end{array}$ & \multicolumn{2}{|c|}{$\begin{array}{c}\text { Experimental } \\
\text { group }\end{array}$} & \multicolumn{2}{c|}{$\begin{array}{c}\text { Control } \\
\text { group }\end{array}$} & Value (T) \\
Calculated & $\begin{array}{c}\text { Level of } \\
\text { significance }\end{array}$ \\
\cline { 3 - 8 } & & $\mathrm{S}$ & $\begin{array}{c}+/- \\
\mathrm{E}\end{array}$ & & & & \\
\hline \hline $\begin{array}{l}\text { The motor } \\
\text { range of the } \\
\text { knee joint }\end{array}$ & $\mathbf{C m}$ & 161.25 & 0.62 & 101.32 & 0.52 & 4.85 & Significance \\
\hline $\begin{array}{l}\text { Frontal } \\
\text { balance }\end{array}$ & Degree & 9.98 & 0.25 & 8.20 & 0.24 & 3.25 & Significance \\
\hline Rear balance & Degree & 10.9 & 0.41 & 8.44 & 0.36 & 3.14 & \\
\hline Balance left & Degree & 9.78 & 0.27 & 7.15 & 0.51 & 3.12 & Significance \\
\hline Balance right & Degree & 9.60 & 0.41 & 7.24 & 0.34 & 3.25 & Significance \\
\hline
\end{tabular}


Follow Table (3)

The significance of the differences between the two dimensional measurements in the level of some functional variables among the patients in the experimental and control groups $N=16$

\begin{tabular}{l|c|c|c|c|c|c|c}
\hline \hline \multirow{2}{*}{ Tests } & \multirow{2}{*}{$\begin{array}{c}\text { Unit } \\
\text { measurement }\end{array}$} & \multicolumn{2}{|c|}{$\begin{array}{c}\text { Experimental } \\
\text { group }\end{array}$} & \multicolumn{2}{c|}{$\begin{array}{c}\text { Control } \\
\text { group }\end{array}$} & $\begin{array}{c}\text { Value (T) } \\
\text { Calculated }\end{array}$ & $\begin{array}{c}\text { Level of } \\
\text { significance }\end{array}$ \\
\cline { 3 - 7 } & & $\mathrm{S}$ & $\begin{array}{c}+/- \\
\mathrm{E}\end{array}$ & & & & \\
\hline $\begin{array}{l}\text { Circumference } \\
\text { of muscles to } \\
\text { leg muscles }\end{array}$ & $\mathbf{C m}$ & 38.21 & 0.98 & 33.98 & 0.31 & 4.62 & Significance \\
\hline $\begin{array}{l}\text { Peripheral } \\
\text { muscles of the } \\
\text { thigh muscles }\end{array}$ & $\mathbf{C m}$ & 45.98 & 0.14 & 39.52 & 0.18 & 4.98 & Significance \\
\hline \hline
\end{tabular}

*Tabular value $(\mathrm{T})$ at the level of significance $(0.05)=1.782$

It is clear from Table (3) that there are statistically significant differences between the averages of the two dimensions of the experimental and control groups at the level of some functional variables among the patients in the experimental and control groups

\section{Discussion of results}

It is clear from Table (1) that there are statistically significant differences between the averages of the tribal and remote measurements at the level of some functional variables in patients with anterior cruciate ligament injury after the surgical procedure.

The researcher attributed this improvement to the proposed program using the Assiut Journal For Sport Science Arts exercises using the hemisphere, The occurrence of the change in the level of locomotor in the infected sample of the study as a result of exposure to the application of the proposed program, which was through the group of exercises isometric and working to bend and extend the knee joint in the last third of the current range of motor within the program Which leads me in the same direction of movement and consistent with the nature of the motor performance of the knee joint.

Stephan (2001) states that balance may be affected by injury and that the most important factors that assist in the incidence of knee injuries is the low balance, especially in the movement of the foot 
movement as the injured party is less balanced because of the presence of the tumor and the impact of severe injury and fixed and dynamic balance exercises are important in Dispose of the tumor and pain and restore the movement and strength of the joint so you should start the exercises of the balance of the fixed and then move the knee joint in all directions but with no pain. (98:22)

And that the foot is exposed to many injuries because of the absorption of many shocks resulting from the intensity of the effort on the foot caused by sports movements such as running and jumping because it is the foot that receives and distributes body weight during the dynamic transition.

The results of this study agree with the study of Nermeen Samih (2012)

Muhammad Kamal (2011) (11) that the interest in balancing exercises for the joints affected directly proportional to the speed of return to the natural state of the joint injured.

The researcher refers to the change in the level of balance among the infected sample of the study as a result of exposure to the application of the proposed program by relying on a set of balanced exercises used on the hemodynamic system of leaps on one foot and two feet,

Which work to increase the stability of the knee joint within the therapeutic program, The shape of the movements of the front, back and side and corresponds to the nature of motor performance of the knee joint.

Ayman Awad (2012) states that the player who suffers from recurrent sprain in the knee joint suffers from the inability to maintain the balance for a long time and therefore the constant and motor balance is weak and there are important factors for the instability of the joint, including muscle weakness as well as defects in self-receptors and affected (65: 3), whether it is the ligament, the joint, or the muscles around the joint.

Abdul-Azim al-Oudali (2004) points out that he will not transmit nerve signals to the nervous system to produce a strong reaction against any recurrence. In addition, balancing and standing on one foot requires input and a system of self-receptors.(52: 8) 
The weakness of the muscles surrounding the knee (the frontal femoral muscle and the posterior femoral muscle) leads to imbalance.

The patient who has a weak balance is faster in the knee joint and has several characteristics, including the inability to maintain the balance and thus be prone to recurrence of the infection. In the knee joint frequently because of the lack of firmness of the knee. $(65: 20)$

The results of this study are consistent with the study of Talal Salem (2010), 5 which stressed the importance of developing balance as an important element in prevention in general and rehabilitation in particular in the injury of the knee joint, which fulfills the hypothesis of the first research

It is clear from Table (2) that there are statistically significant differences between the averages of the tribal and remote measurements at the level of some functional variables in patients with anterior cruciate ligament injury after the surgical procedure for the control group.
The researcher attributed this improvement to the traditional program proposed and applied to the control group Contains general functional exercises to improve motor range and balance without tools.

The increase in muscle mass means increased muscle mass and cross-section. In fact, the increase in the muscle area is due to the increased width of the muscular fibers of the muscle and the growth of muscle size and increase by physical training, especially the use of weight training,

which makes the muscle Respond to this pregnancy through the creation of positive anatomical and functional changes that make it later able to adapt to this new situation. The results of research conducted on athletes and compared with non-athletes, that the muscle fibers fast in the muscles of the thighs in the four-wheeler is the largest pilgrimage $A$ than those of non-athletes or the athletes endurance by $45 \%$. (65:12)

The results of this study are in line with the findings of the Talal Salem study (2010) (5) that the water sports rehabilitation leads to an 
improvement in the strength of the muscles working on the joints after the injury, thus achieving the first hypothesis of the research, which provides for differences of statistical significance between The average of tribal and remote measurements in some functional variables in patients with knee joint changes

It is clear from Table (3) that there are statistically significant differences between the averages of the two dimensions in the experimental and control groups at the level of some functional variables among the patients in the experimental and control groups. These differences are due to the use of the proposed rehabilitation program using the Balance ballAnterior cruciate ligament.

The training sessions are divided into Passive Training, the first stage of rehabilitation for the active member, accompanied by the use of physiotherapy, and Assistive Training, where the therapist helps the patient move the injured part and free active exercises, ,

Resistive Training exercises, which are performed by the patient for the purpose of force using all types of resistors, and the general training exercises take place outside or inside the water (18:35).

The results of this study are consistent with Mohieddin Mohammed (2007). "Sports rehabilitation is the assistance of the injured to restore the functional capacity in the shortest possible time using physiotherapy methods appropriate to the type and severity of the injury. The importance of rehabilitation exercises is based on two main goals: To the arena of competition with the same functional and physical efficiency that it had before the injury and as soon as possible. (18:12)

In this regard, "Amira al-Baroudi" (2013) (2), "Aisha Al-Fateh" (2015) (7) agree that the good planning of training programs with tools - Balance ball- and the regulation of training loads in a scientific manner suitable for the age and training of the research sample In the development of functional and physical abilities, which fulfills the hypothesis of the third research 


\section{Conclusions}

-The proposed program using the Balance ball to improve the level of motor mobility in patients with cutting the front cruciate ligament.

-The proposed program using the Balance ball has improved the level of balance in patients with anterior cruciate ligament injury.

-The proposed program using the Balance ball to improve the level of muscle circumference in patients with anterior cruciate ligament cut.

\section{Recommendations}

-Use of the proposed program using the Balance ball because it has a positive effect on the level of functional benefit in patients with anterior cruciate ligament injury.

-Expand the use of modern rehabilitation methods because of their role in the speed of the return of the injured to the stadiums.

-Training sessions to introduce the importance of the use of aids (Balance ball ) in improving the functional efficiency of the infected.

\section{References}

1-Abdul-Azim Al-Oudly:

"The New in Physical Therapy and Sports Injuries, Dar AlFikr Al-Arabi, Cairo, 2004.

\section{2- Aisha Mohamed Elfatih}

Training program using the Balance ball on the level of some physical variables and skill performance in the sport of fencing, published scientific research, the Faculty of Physical Education Sciences, Faculty of Physical Education, Minia University،

\section{3- Alvinn J. Detterline":} Evaluation And Treatment Of Osteochondritis Dissects Lesions Of The Knee",J Knee Surge ,Vol21,No2,p106114.2008

\section{4- Amira Mohammed Amir} Baroudi: Constructive learning strategy using the Bose Ball and its impact on the level of skill in volleyball published scientific research, Journal of Science and Sports Arts, Faculty of Physical Education for Girls, Helwan University, $2013 \mathrm{~m}$.

5- Ayman Abdullah Awad, "The Effect of Rehabilitation Program on Cutting the Anterior Crusher of the Knee Joint Using Hydrotherapy Training, PhD Thesis, Faculty of Physical Education, Banha University, 2012

6- Brian J. Cole \&": Biologic Joint Reconstruction ",Slack Incorporated, human Kentk< vol21 USA,2008 
7- Carrie Lad cherty, Brent Latnold, Bruce M Gansneder, Chepard H Gerick: Functional Performances Deficits In Volunteers With Functional Ankle Instability", Journal Of Athletic Training, Vol (40), March,2005

8- Carolyn Kisner \& other: Therapeutic Exercise Foundations and Techniques", Fifth edition, Copyright by F. A. Davis Company GFR,2007

9- Charity Ibrahim AlSukkari: "Training of the human body movement, the knowledge facility, Alexandria, 2001.

10- Hani Jafar Abdullah AlSadiq: Effectiveness of using the Balance ball at the level of the attack against the skill of falling on the two men in the wrestlers, published scientific research, Journal of Science and Sports Arts, Faculty of Physical Education for Girls, Helwan University،

\section{1- Mohammed}

Adel

Rushdie: "Mechanic injury of the knee joint" Knowledge facility, Alexandria, 2003.

12- Mohamed Hassan Allawi, Mohamed Nasr El-Din

Radwan: "Tests of motor performance," Dar Al-Fikr AlArabi, 2001.

\section{3- Mohamed Kamal Ali:}

Effect of the proposed rehabilitation program on improving the motor and functional efficiency of the muscles working on the knee joint industrial, Master, Faculty of Physical Education for Boys, Alexandria University, 2004.

14- Mohieddin Mustafa Mohamed: A health program for the rehabilitation of the knee joint and the muscles working after the replacement of the full knee joint, $\mathrm{PhD}$ thesis, Faculty of Physical Education, Tanta University, 2007

\section{5- Nermeen Ahmed Samih:}

A training program using the Balance ball to develop some elements of fitness associated with the skill of correction in basketball, Master, Faculty of Physical Education for Girls, Helwan University, 2012.

16- Ruth Sova: "Aquatic Exercise", Jone \& barteleh publishers, Boston, London, 2003

17- Chatsworth : validation of outcome measures in patients Patellofemoral syndrome", the journal of orthopedic and sports physical tramp, Baltimore, 2000 
18- Games Ashton Miller, Edward Wojtys, Laura Halley: Can Proprioception Really Be Improved by Exercises", sports Thraumatology, Arthroscopy, Vol (9). 2001

19- Osama Mustafa Riad, Hassan Najmi: "Sports Medicine and Physiotherapy, Book Center for Publishing, Cairo, 2001

20- Samia Khalil

Mohammed: "Techniques of Physical Therapy and Rehabilitation of Athletes, Part I, 2007.

\section{1- Stephan G.Pil\& Other} (2001):"Osteochondritis

Dissecans Of The Knee Experiences At The Children
Hospital Of Philadelphia And A Review Of Literature", The University Of Pennsylvania Orthopedic Journal, ,v14,p2533,2001

22-Talal Salem Salem: Knee Injuries and its Relationship to Different Games and Periods of Treatment in Kuwait, Unpublished Master Thesis, Faculty of Physical Education, Banha University, 2010.

23-vodka Strojnik, \& other (2002):"The Effect Of Proprioception Training On Neromuscular Function In Patents With Patellar Pain", molecular Biology Letters ,vol.7,No.1. 